\title{
Assessment of the factors and impact of obese sedentary employee membership in the composite structured exercise program
}

\author{
Godefroid Kusuayi Mabele ${ }^{1}$, (1) Constant Nkiama Ekisawa ${ }^{1}$, \\ (1) Christophe Delecluse ${ }^{2}$, (i) François Lepira Bompeka ${ }^{3}$, \\ Aliocha Nkodila Natuhoyila ${ }^{3}$, ำ Betty Miangindula ${ }^{1}$, 자 Pierre Akilimali ${ }^{4}$
}

\author{
${ }^{1}$ Department of Kinesiology, Department of Physical Medicine and Rehabilitation, Faculty of Medicine, University of Kinshasa, Democratic \\ Republic of Congo. \\ ${ }^{2}$ Faculty of Kinesiology and Rehabilitation Sciences, Biomedical Department, K.U. Leuven, Belgium. \\ ${ }^{3}$ Department of International Medicine, Faculty of Medicine, University of Kinshasa, Democratic Republic of Congo. \\ ${ }^{4}$ School of Public Health of Kinshasa, Faculty of Medicine, University of Kinshasa, Democratic Republic of Congo.
}

\begin{abstract}
The objective is to determine the factors influencing and the impact of obese worker membership in the structured mixed exercise program. Analytical cross-sectional study of 157 obese workers, aged 18 to 59 , randomly selected and subjected to a 3-day, one-day, moderate-intensity, structured exercise program of moderate intensity to high including jogging, aerobic gymnastics, basketball, volleyball, swimming, abdominals and walk of 10,000 not at the rate of three working days and two days of weekend recorded using a pedometer. This program has been combined with low-calorie nutrition education, rich in fiber and vitamins and has been associated with spontaneous physical exercise. The factors influencing the adherence of obese workers to the mixed structured exercise program were measured by the positive personal motivation associated with membership. Motivation to undertake the intervention program resulted from the home exercise program, attendance at appointments, better follow-up of prescribed protocols, and better selfreported adherence. Logistic regression was used to identify independent determinants of adherence to the intervention program. The value of $p<0.05$ defined the threshold of statistical significance. The overall adherence rate of obese workers to the exercise program was $84.1 \%$. Cardiovascular risk factors were
\end{abstract}

significantly higher in the more adherent compared to the less adherent $(p=0.001)$. Obesity, age under 50 , and females were the major determinants of joining the structured mixed exercise program and multiplied by 5 if employees were obese and older. Less than 50 years $(\mathrm{OR}$ aj $=4.9195 \% \mathrm{CI}(1.36-6.14), \mathrm{p}=0.001$ for the obese and OR aj $=4.8795 \% \mathrm{CI}(1.53-6.48), \mathrm{p}=0,000$ for age under 50), and 2 for obese women (OR aj $=2.0695 \% \mathrm{CI}$ (1.23-4.79), $\mathrm{p}=0.000)$. Obesity, female gender, and age under 50 influence and increase obese adherence to the mixed structured exercise program. The latter positively improve the associated cardiovascular, metabolic and behavioral risks in the context of occupational health.

Keywords. Adherence, obese, nutrition, physical exercises, sedentary lifestyle.

\section{Introduction}

Management involves active participation on the part of the patient. Indeed, medical treatments often involve medication taken by the patient at home or a follow-up of general recommendations. The practice of mixed structured physical exercises and diet also generally include the continuation by the participant outside his hours in the prescriber's 
presence, whether by home-based exercises, by the application of modalities of the diet or by following recommendations from the prescriber (Kyngas et al., 2000; Di Matteo et al., 2004).

In the English literature, the terms adhesion often called compliance, translated in the French literature by the observance which is therapeutic adherence. The term compliance is the term most used in the English literature. Compliance is when a person is rigorously following the treatment or program prescribed by a health professional, including adherence to medication and exercise guidelines (Granquist et al., 2010; Cramer et al., 2008; Carr et al., 2001).

Generally applied to the field of medicine only, the most commonly cited definition describes adherence as the patient's behavior in taking medication, following a diet or making lifestyle changes as a result of medical recommendations or prescriptions. More generally, compliance is a set of behaviors on the part of the patient that involves following prescribed treatments or recommendations, but also the action of going to medical appointments (Kardas et al., 2013)

Adherence to treatment is the fact that a person agrees to voluntarily follow all the therapies offered and explained by a health professional. It is added that adherence is a more generic term than adherence involving more the person in the treatment process (Kardas et al., 2013).

According to Lutfey \& Wishner (1999), the use of the term therapeutic adherence increases the patient's independence and involvement in the decision-making process for the development of the treatment plan. Through the use of this term, the patient is systematically considered to be more autonomous and intelligent and has a more active and voluntary role in the management of his treatment, which is much more in line with the current practice of a treatment program adapted physical exercises. Adherence to treatment is then seen as a social and personal problem that extends beyond the medical goals offered solely by the treating professional, thus widening the possible causes of membership deficits and more importantly the possible solutions (Lutfey \& Wishner, 1999). Personal and environmental factors are then considered. Therapeutic adherence refers more to the patient's attitudes and motivations. The intrinsic nature of these elements makes adherence less observable and therefore less objectively measurable (Bassett et al., 2003).

A physical health program of obese sedentary workers is increasingly based on scientific evidence. Indeed, every year, many researches are carried out to improve this program of the health of the physical activities. On the other hand, the literature shows that in order to achieve good treatment outcomes through physical activity, it is not enough for the designer or prescriber to apply scientific evidence to the letter; good program adherence is also necessary for successful practice.

In fact, participants must also get involved in their program and follow the recommendations of their prescriber. The lack of adherence to the program of physical activities or the fact that the participant does not follow the recommendations and the prescription plan given by the kinesiology's, in the field of physical activity health, an omnipresent problem. Despite the large number of stakes involved, no concrete study exists in the literature concerning the adherence of Congolese in general and in particular the Kinshasa employees suffering from obesity.

\section{Methods}

The company called Multimodal Freight Management Office (OGEFREM, acronym) served as a framework for this study. The choice of this company was justified in particular by the relatively better purchasing power of the workers, which is observed by the means of motorized and favorable travel. Staff do most of their work from 7:30 am to 3:00 pm while sitting in front of the computer and / or reading.

The present study was of a quasi-experimental nature of the pre-and post-intervention type carried out from the data collected at the company OGEFREM in the period from November 7, 2014 to November 27, 2015. The study population consists exclusively of all the obese employees of this selected company. The judgment criterion for including an employee was to have no prior 
diagnosis of a cardiovascular risk factor. To this criterion, the following secondary criteria have been added: 1) Have the Body Mass Index (BMI) greater than or equal to $30 \mathrm{~kg} / \mathrm{m}^{2}$; 2 ) be between 18 and 59 years old; 3) Have been employed at the Multimodal Freight Management Office for at least one year of service; 4) Have consented verbally or in writing to participate in our study. The categories of employees below were excluded: 1 ) Pregnant and lactating women; 2) Subjects seriously ill; 3) physically handicapped and mentally ill; 4) Persons diagnosed for unstable cardiovascular pathologies at rest and / or exercise and osteo-articular that may interfere with the practice of physical activity and 5) Consumption of drugs on a daily basis that affect the metabolism of lipids, glucose or the response to training and contraceptive use.

A comprehensive sample of 157 obese, consecutive recruitment based on body mass index greater than or equal to $30 \mathrm{Kg} / \mathrm{m}^{2}$, of which 76 males (48.4\%) and 81 females (51.6\%) aged 18 and more was formed. All participants gave written informed consent for participation in the study. This has been approved by the ethics committee. The confidentiality of the information obtained on the participants of the study was respected. The data collected included socio-demographic characteristics (age and sex), sedentary behavior (setting up more than three hours watching television, working on the computer, and reading).

The effects influencing the adherence of obese sedentary workers to the mixed structured exercise program was measured by the positive personal motivation associated with adherence. In obese sedentary workers, the motivation to undertake the intervention program was derived from the execution of the home exercise program, their attendance at appointments, better follow-up of prescribed protocols and better self-adherence. According to the interpretation of the literature, patient motivation is one of the most important factors that influences therapeutic adherence (Jack et al.,2010; Burkhar et al.,2003; Wolf et al.,2007; Logan et al.,2003; Plotnikoff et al., 2000). However, it is important to consider the type of motivation of the patient as this can influence the degree of adherence. Indeed, being motivated for "bad reasons" can have a minimal or even negative effect on membership. Thus, the motivation can be subdivided into 5 categories of autonomy according to Chan, evolving from less autonomous to more autonomous (Chan et al., 2009): 1) external regulation: I will have problems if I do not participate; 2) introjection: I feel bad if I do not participate; 3) Identification: The program is important to me »4) Integration: The program makes sense and counts for me "5) intrinsic motivation: It is in my best interest to complete the program. The impact of adherence to the intervention program was determined by the proportion (\%) of the motivation to perform the home exercise program, their attendance at appointments, and better follow-up. prescribed protocols, to a better self-reported adherence and according to the 5 categories of autonomy according to Chan, distributed as follows: 1) less adhering: if motivation and autonomy are $\leq 50 \%$ participation in the program and 2) more adherent: if motivation and autonomy are $>50 \%$ participation in the program.

The following anthropometric parameters were measured: the size in $\mathrm{cm}$ was measured using the portable tip of the Seca brand, while the waist circumference in $\mathrm{cm}$ and the hip circumference in $\mathrm{cm}$ by a metric tape. The morbid-fatal risks according to the Ratio Abdo-Hip (RAH) in cm, the weight in $\mathrm{kg}$ and the body composition (total fat mass, muscle mass and intra-abdominal fat) by OMRON Brand Balance Inpedancemeter BF-511 Health care Country Netherlands / Netherlands. $\mathrm{BMI}$ in $\mathrm{kg} / \mathrm{m} 2$ was calculated calculating the mass (expressed in kilograms) divided by the square of the person's height (in meters). The following lipid parameters: HDL-C, LDC-C, Total cholesterol and triglycerides were measured in fasted employees for at least 12 hours on serum by clinical laboratory biologists at MOKOLE Hospital in Mont Ngafula, Kinshasa using the method enzymatic and Elitech colorimetric kits. (Sees, France). PA was measured after 5 minutes of sitting relaxation on the left arm, worn in the heart, using a mercury sphygmomanometer; three consecutive doses at one minute intervals were performed and their mean defined the PA of the patient. PAS and PAD 
corresponded respectively to the sounds of Korotkoff 1 and 5. A poor body composition was defined as follows: total body fat $\geq 20 \%$ in men and $32 \%$ in women, abdominal (visceral) fat $>9 \%$ in men and women and lean mass (Muscle) $\leq 33.3 \%$ for men and 3 to $24.4 \%$ for women (Browning et al.,2010; Gallagher et al.,2000)

The metabolic syndrome was defined according to the US National Cholesterol Education Program (NCEP-ATPIII, 2001), by the presence of at least 3 of the following risk factors: waist circumference $\geq$ $94 \mathrm{~cm}$ in humans and $80 \mathrm{~cm}$ in women; Arterial pressure $\geq 130 / 85 \mathrm{mmHg}$; Triglycerides $\geq 150 \mathrm{mg}$ / dl; HDL cholesterol $<40 \mathrm{mg} / \mathrm{dl}$ in men, $<50 \mathrm{mg} / \mathrm{dl}$ in women; Fasting blood glucose $\geq 110 \mathrm{~g} / \mathrm{l}$ (Contegal et al., 2005). The intervention program lasted six months. During these six months, the participants followed a structured high volume mixed exercise program combined with nutrition education in the form of dietary counseling. These structured physical exercises were practiced on the Basketball court, around the pool and in the swimming pool of the Teresitas Sisters' Recreation Center of the 10th Street Limeté industrial, city of Kinshasa province under the supervision of the Kinesiologists. This structured exercise program included jogging exercises; aerobic gymnastics; Ball basketball; volley ball; Swimming; Abdo, cuise and buttock and walk of 10000 not recorded using a pedometer. These have been associated with a low-calorie nutritional education, high in fiber and vitamins for three working days (Tuesday, Friday and Thursday) and two days of weekend on a weekly basis (Saturday and Sunday). The sessions lasted one hour, of moderate to high intensity, including two or more types of mixed exercises (aerobic and / or anaerobic endurance) associated with spontaneous physical exercises supervised by prescribers of physical exercises and combined with physical exercise. Nutrition education (low calorie, high in fiber and vitamins) and an introduction to various sports or physical leisure activities. Participants were encouraged to increase their energy expenditure related to spontaneous exercises. Each participant had their own pedometer and aimed to reach 10,000 steps per day in order to gradually increase the level of physical activity on odd days (Monday, Wednesday and
Friday). Thus, he had to fill in a logbook in which he indicated the number of steps, the volume of activity, the distance traveled and / or the physical activity of leisure carried out. At the end of each month, the participants reviewed the various stakeholders to carry out the same evaluations they had undergone before the intervention.

The study data was coded on Excel 2010 and analyzed on the SPSS 21.0 software. Data are expressed as mean \pm standard deviation (SD) for normally distributed and continuous variables (interquartile space, EIQ) for non-normally distributed variables. The qualitative variables are expressed in absolute frequency (relative frequency in percentage). Student's t-test was used to compare the averages of 2 groups; the Mann Whitney $U$ test was used to compare the medians of 2 groups.

The independent determinants of interventional adherence were identified using logistic regression, $p<0.05$ defining the statistical significance threshold. The protocol of the study was submitted and approved by the ethics committee of the Ministry of Public Health of the Democratic Republic of Congo. Respect for the principles of Helsinki

\section{Results}

The overall frequency of adherence of obese employees to the intervention program is shown in Figure 1.

Figure 1 indicates that the overall frequency of employee adherence to the intervention program was $84.1 \%$. The socio-demographic characteristics of adherents are summarized in Table 1.

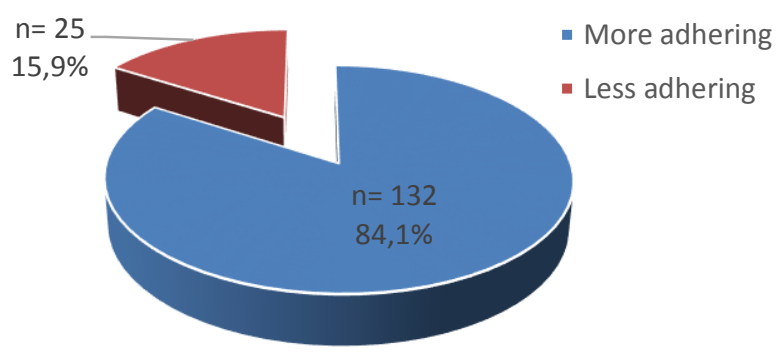

Figure 1. Frequency of Obese Employee Adherence to Mixed Structured Physical Exercise Program. 
Among the 157 obese employees, there were 88 women $(66.7 \%)$ and 44 men $(33.3 \%)$, a sex ratio $\mathrm{H} /$ $\mathrm{F}$ of 2 . Youth adhered significantly more than old $(p=0.001)$. The average age of the most adherent was $41.6 \pm 8.4$ years against $50.6 \pm 5.5$ years for the less adherent. This table also shows that, the more the employees were young obese, that they had the total body fat, visceral high and the weak muscular mass, more than adhered significantly $(p=0.000)$ to the program of intervention The factors of Cardiovascular risk as a function of obese employee adherence to the intervention program is summarized in Table 2.

Cardiovascular risk factors were significantly higher among obese employees who were more adherent than those who were less adherent $(84.1 \%$ vs. $15.9 \%, p<0.001)$. Frequency of employee adherence to the intervention program increased significantly with age $(p=0.001)$, obesity $(p=0.005)$ and very high total body fat $(\mathrm{p}=0.005)$.
Table 4 outlines the determinants of adherence to the intervention program in univariate and multivariate analysis among obese employees.

In unified mixed analysis, obesity, age under 50, female high total body fat emerged as determinants of adherence to the restructured physical exercise program of mixed Kinshasa employees with obesity. After adjustment, only obesity, age less than 50 years, and female sex were major major determinants of joining the structured mixed exercise program and increased adherence by 5 if employees were obese and were under age 50 (OR $\mathrm{aj}=4.9195 \% \mathrm{CI}(1.36-6.14), \mathrm{p}=0.001$ for the obese and OR aj $=4.8795 \%$ CI $(1.53-6,48), p=0.000$ for the age of less than 50 years, and by 2 in obese women $(\mathrm{OR}$ aj $=2.06$ 95\% CI (1.23-4.79), $\mathrm{p}=0.000)$. Table 4 presents the impact of adherence after the mixed exercise program among obese employees in Kinshasa.

\section{Table 1}

General characteristics of the study population according to adhesion.

\begin{tabular}{|c|c|c|c|c|}
\hline Variables & All (n=157) & More Adherent ( $\mathrm{n}=132)$ & Less Adherent $(\mathrm{n}=25)$ & $\mathrm{p}$ \\
\hline Age (year) & $42.7 \pm 8.7$ & $41.6 \pm 8.4$ & $50.6 \pm 5.5$ & $0.001^{*}$ \\
\hline Sex & & & & $0.001^{*}$ \\
\hline Male & $66(42.0)$ & $44(33.3)$ & $22(88.0)$ & \\
\hline Female & $91(58.0)$ & $88(66.7)$ & $3(12.0)$ & \\
\hline BMI $\left(\mathrm{kg} / \mathrm{m}^{2}\right)$ & $32.3 \pm 6.2$ & $34.7 \pm 5.7$ & $30.0 \pm 7.9$ & 0.051 \\
\hline Waist $(\mathrm{cm})$ & $94.8 \pm 12.9$ & $95.2 \pm 13.0$ & $92.7 \pm 12.5$ & 0.376 \\
\hline PAS (mmHg) & $137.7 \pm 23.4$ & $135.4 \pm 21.0$ & $140.4 \pm 31.9$ & 0.018 \\
\hline PAD (mmHg) & $82.8 \pm 14.9$ & $81.9 \pm 13.9$ & $87.4 \pm 19.0$ & 0.095 \\
\hline Glycaemia (mg/dl) & $126.3 \pm 46.9$ & $125.9 \pm 46.5$ & $128.4 \pm 50.2$ & 0.806 \\
\hline Total Cholesterol (mg/dl) & $221.6 \pm 50.5$ & $221.0 \pm 52.3$ & $225.1 \pm 40.0$ & 0.713 \\
\hline HDL-C (mg/dl) & $69.9 \pm 19.6$ & $69.8 \pm 20.1$ & $70.4 \pm 16.9$ & 0.875 \\
\hline Triglycerides (mg/dl) & $161.9 \pm 57.2$ & $163.3 \pm 56.8$ & $154.8 \pm 60.3$ & 0.497 \\
\hline Total Fat (\%) & $38.5 \pm 11.3$ & $40.6 \pm 10.4$ & $27.5 \pm 10.0$ & $0.000^{*}$ \\
\hline Muscular Mass (\%) & $28.6 \pm 6.6$ & $27.6 \pm 6.4$ & $33.9 \pm 4.9$ & $0.000^{*}$ \\
\hline
\end{tabular}

${ }^{*} p<0.05$ 


\section{Table 2}

Cardiovascular risk factors for adherence to the intervention program.

\begin{tabular}{|c|c|c|c|c|}
\hline Variables & All $(n=157)$ & More Adherent $(n=132)$ & Less Adherent $(n=25)$ & $\mathrm{p}$ \\
\hline Age $\geq 50$ years & $47(29.9)$ & $32(24.2)$ & $15(60.0)$ & $0.001^{*}$ \\
\hline Overweight & $37(23.6)$ & $28(21.2)$ & $9(36.0)$ & 0.093 \\
\hline Obesity & $70(44.6)$ & $65(49.2)$ & $5(20.0)$ & $0.005^{*}$ \\
\hline \multicolumn{5}{|l|}{ CRFLMS } \\
\hline Abdominal Obesity & $101(64.3)$ & $88(66.7)$ & $13(52.0)$ & 0.121 \\
\hline High Blood Pressure & $55(35.0)$ & $46(34.8)$ & $9(36.0)$ & 0.541 \\
\hline High Cholesterol & $88(56.1)$ & $75(56.8)$ & $13(52.0)$ & 0.409 \\
\hline HDL - C Low & $20(12.7)$ & 18(13.6) & $2(8.0)$ & 0.345 \\
\hline High Triglycerides & $96(61.1)$ & $82(62.1)$ & $14(56.0)$ & 0.359 \\
\hline \multicolumn{5}{|l|}{ Body Composition } \\
\hline Body Fat & & & & $0.005^{*}$ \\
\hline Normal & $14(8.9)$ & $8(6.1)$ & $6(24.0)$ & \\
\hline High & $12(7.6)$ & $8(6.1)$ & $4(16.0)$ & \\
\hline Very High & $131(83.4)$ & $116(87.9)$ & $15(60.0)$ & \\
\hline Visceral Fat & & & & 0.602 \\
\hline Normal & $79(50.3)$ & $64(48.5)$ & $15(60.0)$ & \\
\hline High & $45(28.7)$ & $39(29.5)$ & $6(24.0)$ & \\
\hline Very high & $33(21.0)$ & $29(22.0)$ & $4(16.0)$ & \\
\hline Muscular mass & & & & 0.374 \\
\hline Low & $75(47.8)$ & $67(50.8)$ & $8(32.0)$ & \\
\hline Normal & $62(39.5)$ & $48(36.4)$ & $14(56.0)$ & \\
\hline High & $12(7.6)$ & 10(7.6) & $2(8.0)$ & \\
\hline Very high & $8(5.1)$ & $7(5.3)$ & $1(4.0)$ & \\
\hline
\end{tabular}

* $p<0.05$; CRFLMS: Cardiovascular Risk Factors Linked Metabolic Syndrome

Overall, obesity-related cardiovascular and metabolic risk factors were statistically low among obese employees most adherent to the mixedstructured versus at least adherent exercise program $(\mathrm{p}<0.001)$.

\section{Discussion}

This study was conducted to determine the influencing factors and the impact of adherence of obese employees to the mixed structured exercise program.

The overall incidence of obese employee adherence to the exercise program was $84.1 \%$.
Cardiovascular risk factors were significantly higher in adherents than in those who were less adherent and increased with age under 50 , obesity and very high total body fat.

Obesity, age under 50, and female sex were major key determinants of obesity worker adherence to the mixed structured exercise program and increased 5-fold adherence if workers were obese if they were under age 50 and twice if they were female. Obesity-related cardiovascular and metabolic risk factors were statistically low among the obese employees most adherent to the mixed-structured versus at least adherent exercise program. 
Table 3

Determinants of adherence to the intervention program in univariate and multivariate analysis among employees obese to the program.

\begin{tabular}{|c|c|c|c|c|}
\hline \multirow{2}{*}{ Variables } & \multicolumn{2}{|c|}{ Univariate Analysis } & \multicolumn{2}{|c|}{ Multivariate Analysis } \\
\hline & $\mathrm{p}$ & OR (95\%IC) & $\mathrm{p}$ & ORa (95\% IC) \\
\hline \multicolumn{5}{|l|}{ Age } \\
\hline$\geq 50$ years & 1 & 1 & 1 & 1 \\
\hline$<50$ years & 0.001 & $4.68(1.92-11.45)$ & 0.000 & $4.87(1.53-6.48)$ \\
\hline \multicolumn{5}{|l|}{ Sex } \\
\hline Male & 1 & 1 & 1 & 1 \\
\hline Female & 0.000 & $4.66(1.16-9.67)$ & 0.000 & $2.06(1.23-4.79)$ \\
\hline \multicolumn{5}{|l|}{ Obesity } \\
\hline No & 1 & 1 & 1 & 1 \\
\hline yes & 0.010 & $5.88(2.38-10.95)$ & 0.001 & $4.91(1.36-6.14)$ \\
\hline \multicolumn{5}{|l|}{ Body fat } \\
\hline Normal & 1 & 1 & 1 & 1 \\
\hline High & 0.001 & $4.83(1.86-12.57)$ & 0.535 & $1.79(0.39-2.63)$ \\
\hline
\end{tabular}

\section{Table 4}

Impact of adherence after the mixed exercise program among obese employees in Kinshasa.

\begin{tabular}{|c|c|c|c|c|}
\hline Variables & All & More Adherent & Less Adherent & $\mathrm{p}$ \\
\hline BMI $\left(\mathrm{kg} / \mathrm{m}^{2}\right)$ & $24.5 \pm 2.1$ & $23.8 \pm 0.9$ & $31.0 \pm 0.9$ & $<0.001$ \\
\hline Waist (cm) & $90.7 \pm 3.2$ & $89.6 \pm 1.7$ & $99.3 \pm 0.8$ & $<0.001$ \\
\hline PAS (mmHg) & $125.7 \pm 3.4$ & $124.5 \pm 2.0$ & $134.3 \pm 2.9$ & $<0.001$ \\
\hline PAD (mmHg) & $81.1 \pm 1.5$ & $80.8 \pm 1.2$ & $85.0 \pm 0.7$ & $<0.001$ \\
\hline Glycaemia (mg/dl) & $101.4 \pm 4.9$ & $99.7 \pm 1.2$ & $116.8 \pm 1.3$ & $<0.001$ \\
\hline HDL- C (mg/dl) & $44.2 \pm 2.3$ & $45.1 \pm 1.1$ & $38.6 \pm 0.5$ & $<0.001$ \\
\hline Triglycerides (mg/dl) & $136.3 \pm 6.6$ & $133.8 \pm 2.4$ & $152.4 \pm 4.8$ & $<0.001$ \\
\hline Total fat (\%) & $28.9 \pm 1.3$ & $28.7 \pm 1.0$ & $31.8 \pm 2.1$ & $<0.001$ \\
\hline Visceral fat (\%) & $7.2 \pm 0.8$ & $6.9 \pm 0.3$ & $9.5 \pm 0.5$ & $<0.001$ \\
\hline Lean mass (\%) & $44.1 \pm 2.3$ & $45.0 \pm 0.8$ & $38.1 \pm 1.3$ & $<0.001$ \\
\hline
\end{tabular}

This is consistent with several research findings suggesting that when subjects over the age of 50 do not join the exercise program, it is often because they believe that this is not necessary for this age when life expectancy is reduced. Age-related physiological changes increase the risk of adverse effects from adherence to the exercise program. The female sex influences a better adherence to the exercise program structured with respect to the male sex (Tourette-Turgis et al., 2010; Tarquinio et al., 2007).
Adherence to treatment therefore reflects the real involvement of the participant in the choice of the exercise program that is offered to him and thus recognizes his autonomy. According to literature, adherence to drug and non-drug prescriptions is estimated to be around $50 \%$. It increases the feeling of pleasure to win, to play with friends, to be good, to socialize. Some people will say they are too tired or will prefer rest and relaxation during leisure time. Currently, the studies confirm that $80 \%$ of patients with chronic pathology do not adhere to their prescribed management program to obtain 
optimal benefits. Oppert et al. showed that adherence to the prescribed physical activity program had a positive impact on patients with chronic pathology (Oppert et al., 2007). The Desbrus \& Misdrahi study found that obesity is a somatic factor influencing adherence to the prescribed exercise program (Desbrus-Qochih et al., 2012; Misdrahi et al., 2012). Our results also reflect the multiple studies that indicate that age, obesity, and gender are factors that influence the adherence of individuals who wish to lose weight or be in better physical condition through structured exercise programs mixed (Rostan et al., 2011 ; Simon et al., 2005).

The more effective exercise a program is, the more obese patients adhere to. A good understanding of the state of health and prescribed programs also plays an important role in membership. Frequent prescription changes and the multiplicity of prescribers and the undesirable effects of physical exercise are important causes of poor adherence. Non-drug prescriptions such as physical activity and diet changes are very often poorly observed as they imply a change of lifestyle. The more well prescribed and administered the program, the better the adherence, especially when it improves the symptoms (Puel et al., 2010).

\section{Conclusion}

Obesity, female sex, and the age of less than 50 influence and increase the obese adherence to the mixed structured exercise program five times. These have the positive impact on the associated cardiovascular, metabolic and behavioral risk factors in the context of occupational health.

\section{Conflict of Interest}

The authors declare that there are no conflicts of interests.

\section{References}

Bassett SF. The assessment of patient adherence to physiotherapy rehabilitation. New Zeeland Journal of Physiotherapy, 2003; 30(2): 60-66.

Browning LM, Hsieh SD, Ashwell M. A systematic review of waist-to-weight ratio as a screening tool for the prediction of cardiovascular disease and diabetes: 0.5 could be a suitable global boundary value. Nutr Res Rev, 2010; 23: 247-269.

Burkhart PV, Sabate E. Adherence to long-term therapies: evidence for action. Journal of nursing scholarship: an official publication of Sigma Theta Tau International Honor Society of Nursing / Sigma Theta Tau, 2003; 35(3): 207.

Carr A. Barriers to the effectiveness of any intervention in OA. Best practice \& Research Clinical Rheumatology, 2001; 15(4): 645-656.

Chan DK, Lonsdale C, Ho PY, Yung PS, Chan KM. Patient motivation and adherence to post surgery rehabilitation exercise recommendations: the influence of physiotherapists' autonomy-supportive behaviors. Arch Phys Med Rehabil, 2009; 90(12): 1977-1982.

Contegal F, Osseby G-V, Menassa M, Rouaud O, Benatru I, Giroud M. La relation entre Hypertension arterielle et Accidents Vasculaires Cérébraux: une équation modifiable. La Lettre du Cardiologue, 2005; 381: 26-29.

Cramer JA, Roy A, Burrell A, Fairchild CJ, Fuldeore MJ, Ollendorf DA, Wong PK. Medication compliance and persistence: terminology and definitions. Value in Health, 2008; 11(1): 44-47.

Desbrus-Qochih A, Cathébras P. Obéir ou adhérer? L'observance thérapeutique en question. Elsevier Masson, 2012; 4(34): 111-122.

Di Matteo MR. Variations in patients' adherence to medical recommendations: a quantitative review of 50 years of research. Medical Care, 2004; 42(3): 200209.

Gallagher D, Heymsfield SB, Heo M, Jebb SA, Murgatroyd PR, Sakamoto Y. Healthy percentage body fat ranges: an approach for developing guidelines based on body mass index. Am J Clin Nutr, 2000; 72(3): 694-701.

Granquist MD, Gill DL, Appaneal RN. Development of a measure of rehabilitation adherence for athletic training. Journal of Sport Rehabilitation, 2010; 19(3): 249-267.

Jack K, Mc Lean SM, Moffett JK, Gardiner E. Barriers to treatment adherence in physiotherapy outpatient clinics: a systematic review. Manual Therapy, 2010; 15(3): 220-228. 
Kardas P, Lewek P, Matyjaszczyk M. Determinants of patient adherence: a review of systematic reviews. Frontiers in Pharmacology, 2013; 4: 91.

Kyngas H, Duffy ME, Kroll T. Conceptual analysis of compliance. Journal of Clinical Nursing, 2000; 9(1): 512.

Logan D, Zelikovsky N, Labay L, Spergel J. The Illness Management Survey: identifying adolescents' perceptions of barriers to adherence. Journal of Pediatric Psychology, 2003; 28(6): 383-392.

Lutfey KE, Wishner WJ. Beyond "compliance" is "adherence". Improving the prospect of diabetes care. Diabetes care, 1999; 22(4): 635-639.

Misdrahi D. L'observance thérapeutique: un objectif essentiel. L'Encéphale, 2006; 32(6): 1076-1079.

Oppert JM. Exercice du corps: une arme contre les maladies chroniques. La santé de l'homme. INPES, 2007; 387: 21-23.

Plotnikoff RC, Brez S, Hotz SB. Exercise behavior in a community sample with diabetes: understanding the determinants of exercise behavioral change. The Diabetes Educator, 2000; 26(3): 450-459.
Puel MA. Comprendre l'inobservance: l'approche Balint. La Revue du Praticien Médecine Générale, 2010; 24(847): 644-646.

Rostan F, Simon C, Ulmer Z. Promouvoir l'activité physique des jeunes. Elaborer et développer un projet de type Icaps. Saint-Denis: Inpes, coll. Sante en action, 2011.

Simon C, Riviere D, Guezennec CY, Oppert JM. Activite physique: arguments scientifiques, pistes pratiques. Ministère de la santé, de la jeunesse, des sports et de la vie associative, 2005.

Tarquinio C, Tarquinio MP. L'observance thérapeutique: déterminants et modèles théoriques. Pratiques Psychologiques, 2007; 13(1): 1-19.

Tourette-Turgis T. Le degré d'observance n'est pas corrèle à la sévérité de la maladie. Le Concours Médical-Education Thérapeutique, 2010; 132: 19-20.

Wolf MS, Davis TC, Osborn CY, Skripkauskas S, Bennett CL, Makoul G. Literacy, self-efficacy, and HIV medication adherence. Patient Education and Counseling, 2007; 65(2): 253-260. 